\title{
Design and Development of Coupling for Unequal Torque System
}

\author{
Dilip K. Padhal ${ }^{1}$, Prashant N. Awachat ${ }^{2}$, Ashwin Y. deogade ${ }^{3}$ \\ ${ }^{I}$ (Student: Department of Mechanical Engineering, G. H. Raisoni Academy of Engg. \& Technology Nagpur, \\ India) \\ ${ }^{2,3}$ (Asst. Professor: Department of Mechanical Engineering, G. H. Raisoni Academy of Engg. \& Technology \\ Nagpur, India)
}

\begin{abstract}
The problems occurs at the steel industries, as the overall subject of this paper is the frequent failure of output shaft of gear motor at the pay-off reel and design and development of new type of coupling which will operates according to the situation of the nature of the rotation of pay-off reel rotation and the nature of the rotation of the $4 H I$ cold rolling mill and which will perform efficient working under maximum torque condition without fail. As the mechanism used in the coupling is a ratchet pawl mechanism which work is to provide only one directional rotation and restrict the other. Also the use of spring loaded inserts to, which when reverse motion required, mechanism to engage the coupling hence the newly designed coupling is best suitable as per the nature of the rotation of the pay-off and 4 HI cold rolling mill.
\end{abstract}

Keywords: Pay-off reel, 4 HI cold rolling mill, Gear motor, Coupling, Ratchet and pawl mechanism.

\section{Introduction}

The gear motor is used in cold rolling mill to give motion to the Pay-off reel which is movable with automatic guide table also un-wrapping the coil and the beginning of the process. Pay-off is the standby unit to reduce feeding time of the coil to the cold rolling mill. A cold rolling mill, also known as a reduction mill or mill, has a common construction independent of the specific type of rolling being performed. Cold rolling occurs with the metal below its recrystallization temperature (usually at room temperature), which increases the strength via strain hardening up to $20 \%$. It also improves the surface finish and holds tighter tolerances. Commonly coldrolled products include sheets, strips, bars, and rods, these products are usually smaller than the same products that are hot rolled. Because of the smaller size of the work pieces and their greater strength, as compared to hot rolled stock, four-high or cluster mills are used. Cold rolling cannot reduce the thickness of a work piece as much as hot rolling in a single pass. Cold-rolled sheets and strips come in various conditions: full-hard, half-hard, quarter-hard, and skin-rolled. Full-hard rolling reduces the thickness by $50 \%$, while the others involve less of a reduction. Skin-rolling, also known as a skin-pass, involves the least amount of reduction: $0.5-1 \%$. It is used to produce a smooth surface, a uniform thickness, and reduce the yield point phenomenon. It is also used to break up the spangles in galvanized steel. Skin-rolled stock is usually used in subsequent cold-working processes where good ductility is required. Other shapes can be cold-rolled if the cross-section is relatively uniform and the transverse dimension is relatively small. Cold rolling shapes requires a series of shaping operations, usually along the lines of sizing, breakdown, roughing, semi-roughing, semi-finishing, and finishing. If processed by a blacksmith, the smoother, more consistent, and lower levels of carbon encapsulated in the steel makes it easier to process, but at the cost of being more expensive.

\section{Force analysis of shaft of gear motor}

The shaft of gear motor goes failure at the weakest section due to overloading, a tangential load act by the metal sheet i.e. torque of cold rolling mill that comes over the Pay-off reel up to $30000 \mathrm{Nm}$, self-torque 1281 $\mathrm{Nm}$, and bending loading. Also it was found that casing of gear motor goes failure, i.e. it broke. The Gear motor is of $5.5 \mathrm{KW}$ and $41 \mathrm{rpm}$ and that of Cold rolling mill driving motor is of $1000 \mathrm{KW}$ and initial rpm of motor is $200 \mathrm{mpm}$ i.e. meter per minute. The shaft of gear motor goes failure in duration of 1-2 months and each motor cost up to 60,000 Indian rupees. Due to periodic failure of gear motor, company changed the gear motor with separate gear box and motor. One of the reasons of failure is lack of concentration of worker while working.

In Continuous process industry many types of roll are used for various applications; however process rolls used are classified in to two as working \& conveying. Working rolls are used for changing the product being process. This included cold rolling mill, hot rolling mill rolls used for reduction of sheet thickness \& shape. Printing press rolls used for transferring pattern to product. Corrugation rolls used for changing the profile of sheet. Conveying rolls are mainly having application of transferring product from one place to other. This type rolls are smaller diameter and are generally non driven to large diameter used for transferring sheets, paper, and textile products in continuous process industry. The gear motor is used in pay-off reel to wound the metal coil, that motor is connected with Pinch roll of pay-off reel by claw coupling. One lever provided for 
engage and dis-engage of shaft of gear motor. Pinch rolls each of diameter $250 \mathrm{~mm}$. Shaft of gear motor is of SAE4140 i.e. 197 BHN hard. Power of gear motor is $5.5 \mathrm{KW}$ and $41 \mathrm{rpm}$ and that shaft is a step shaft largest diameter of $60 \mathrm{~mm}$ and end diameter $40 \mathrm{~mm}$.

\section{A. Force Acting On The Shaft Of Gear Motor}

Stress Raiser in shaft due to various parameters that are acting on shaft of Gear motor is;

a. Shear stresses due to torque transmission by motor of $5.5 \mathrm{KW}$

b. Bending stresses due to forces acting by,

i) Weight of Pinch roll

ii) Weight of sheet

iii) Weight of shaft itself

iv) Sheet tension on forward direction when main system starts with full

c. Stresses due to combined torsional and bending load

\section{B. Stress Analysis Of Shaft Of Gear Motor}

The stress analysis for the shaft of gear motor is carried out for static analysis in the following ways,

1) Analytical Analysis and

2) Finite Element Analysis.

For the analysis the technical specifications are shown in table 4.1 in which the total length and other parameters are mentioned and also seen in figure 4.1. For the static analysis the shaft is considered like a horizontal cantilever shaft fixed at its one end. The forces acting over the bridle roll has been designed and used for analysis of shaft. The strip tension on forward \& backward is treated as belt tension. The static stress analysis for the shaft of gear motor is as follows.

Table I

\begin{tabular}{|c|c|c|}
\hline \multicolumn{3}{|c|}{ Available Data } \\
\hline Motor Specification & Gear motor & Motor Of Cold Rolling Mill \\
\hline Motor Make & PBL Motor & Kirloskar \\
\hline Output shaft Diameter in mm & $60 \mathrm{~mm}$ & $200 \mathrm{~mm}$ \\
\hline RPM & $41 \mathrm{rpm}$ & $382 \mathrm{rpm}$ (Initial) \\
\hline Power in KW & $5.5 \mathrm{KW}$ & $1200 \mathrm{KW}$ \\
\hline Torque in N-m & 1281 & 30000 \\
\hline
\end{tabular}

Table II

\begin{tabular}{|c|c|c|c|}
\hline \multirow{4}{*}{ Diameter } & & Pay-Off 4 HI & Cold Rolling Mill \\
\hline & Pinch Roll & $250 \mathrm{~mm}$ & \\
\cline { 2 - 4 } & Work Roll & & $250 \mathrm{~mm}-410 \mathrm{~mm}$ \\
\hline \multirow{3}{*}{ Length } & Back up Roll & & $1150 \mathrm{~mm}-1250 \mathrm{~mm}$ \\
\cline { 2 - 4 } & Pinch Roll & $1550 \mathrm{~mm}$ & \\
\cline { 2 - 4 } & Work Roll & & $1550 \mathrm{~mm}$ \\
\hline \multirow{3}{*}{ Weight } & Back up Roll & & $1550 \mathrm{~mm}$ \\
\cline { 2 - 4 } & Pinch Roll & $500 \mathrm{~kg}$ & $1000-3500 \mathrm{~kg}$ \\
\cline { 2 - 4 } & Work Roll & & $18000-25000 \mathrm{~kg}$ \\
\hline \multirow{3}{*}{ No. of } & Back up Roll & & 2 \\
\cline { 2 - 4 } & Pinch Roll & & 2 \\
\cline { 2 - 4 } & Work Roll & & $750000 \mathrm{~kg}$ \\
\hline Load/ Pressure & Back up Roll & 2 & 2 \\
\hline & Acted by each Cylinder & & \\
\hline
\end{tabular}

\section{Static Analysis Of Shaft Of Gear Motor For Sudden Failure}

I. Design Torque of shaft of Gear motor

Power of Gear motor $=7.5 \mathrm{HP}=5.5 \mathrm{KW}$

Rpm of gear motor $=41 \mathrm{rpm}$

Therefore Power of shaft, $\mathrm{P}=(2 \pi \mathrm{NT}) / 60$

$\mathrm{T}=2751 \mathrm{~N}-\mathrm{m}$ 
$\mathrm{K} 1$ - Load Factor

\section{Design Torque of motor of Cold rolling Mill}

While the pay-off en-gauge with main rolling mill, as pay-off is used for providing the coil to the main rolling mill system, and at instance that pay-off get dis-en-gauged, while during the dis-en-gauging the pay off whole torque of mail rolling mill comes on the pay of and shaft of gear motor ,that drives the pay-off system goes failure. So, Power of motor that drives the main rolling mill $\quad \mathrm{P}=1200 \mathrm{KW}$

Initial rotation of rolls of main rolling mill is up to $300 \mathrm{mpm}$

Rpm of motor $=300000 / 1288=232 \mathrm{rpm}$

Power of motor $\mathrm{P}=(2 \pi \mathrm{NT}) / 60 \mathrm{Kl}$

$T_{2}=108664 \mathrm{~N}-\mathrm{m}$

III. Torque Transmitted from main CRM system to the Roll of Pay-off System through metal Sheet in the form of tangential Force

$\mathrm{Ft}=\mathrm{T} / \mathrm{R} 1$

$\mathrm{Ft}=530068 \mathrm{~N}$

As that much amount of force exerted by sheet on the Roll of Pay-off System

Hence Total Amount of Torque on the Roll of Pay-off is,

$\mathrm{Ft} 1=\mathrm{T} 2 / \mathrm{R} 2 \quad \mathrm{~T} 2=15902 \mathrm{~N}-\mathrm{m}$

Material and their properties of shaft of gear motor

As considering Factor of Safety i.e. F.S $=2$

Therefore Tensile /Bending stresses in shaft

$\sigma_{\mathrm{b}}=\sigma_{\mathrm{t}}=\mathrm{S}_{\mathrm{yc}} / \mathrm{FS}=340 \mathrm{Mpa}$

And Shear stresses in shaft

$\tau=\mathrm{S}_{\mathrm{ys}} / \mathrm{FS}=187.5 \mathrm{Mpa}$

For Maximum shear force and bending moment

$\mathrm{R}_{\mathrm{a}}+\mathrm{R}_{\mathrm{b}}=11438$

Taking moment@ A

$\mathrm{R}_{\mathrm{b}} * 1.55=58.86 * 1.88+11438 * 1.55 / 2$

$1-$ length of span $=1.55 \mathrm{~m}$

$\mathrm{R}_{\mathrm{b}}=5618 \mathrm{~N}$

$\mathrm{R}_{\mathrm{a}}=11438-5618=5820 \mathrm{~N}$

Equivalent Twisting Moment

$\mathrm{T}_{\mathrm{e}}=\sqrt{ }\left(\mathrm{M}^{2}+\mathrm{T}^{2}\right)$

$\mathrm{T}_{\mathrm{e}}=16470 \mathrm{~N}-\mathrm{m}$

Equivalent Bending Moment

$\mathrm{Me}=1 / 2\left(\mathrm{M}+\sqrt{ }\left(\mathrm{M}^{2}+\mathrm{T}^{2}\right)\right)$

$\mathrm{Me}=10380 \mathrm{~N}-\mathrm{m}$

Stresses induced in the shaft due to Bending Moment

$\sigma_{\mathrm{b}}=489 \mathrm{~N} / \mathrm{mm} 2>$ Allowable bending stresses $=340 \mathrm{~N} / \mathrm{mm} 2$

Stresses induced in the shaft due to Twisting Moment

$\tau=388.33 \mathrm{~N} / \mathrm{mm}^{2}>$ Allowable Shear Stresses $=187.5 \mathrm{~N} / \mathrm{mm}^{2}$

\begin{tabular}{|c|c|c|c|}
\hline Stress & Allowable stress & Analytical & Software \\
\hline Max. Shear stress & $187.5 \mathrm{Mpa}$ & $388.33 \mathrm{Mpa}$ & $472 \mathrm{Mpa}$ \\
\hline Max. Bending stress & $340 \mathrm{Mpa}$ & $489 \mathrm{Mpa}$ & $512 \mathrm{Mpa}$ \\
\hline
\end{tabular}

Table III Comparison between allowable stresses and analytical stresses

From the table III the maximum shear stress for impact loading is more than allowable shear stress calculated by taking factor of safety 2 as per design data book. This will lead to shaft failure because of impact loading.

\section{A. Axis Symmetric Loading}

\section{Validation Using Finite Element Method}

Problems involving three dimensional axis symmetric solids subjected to axis symmetric loading reduce to two dimensional problems. Because of total symmetry about $\mathrm{z}$ axis all deformations and stresses are independent of rotational angle. Thus, the problem needs to be looked at as two-dimensional problem. 


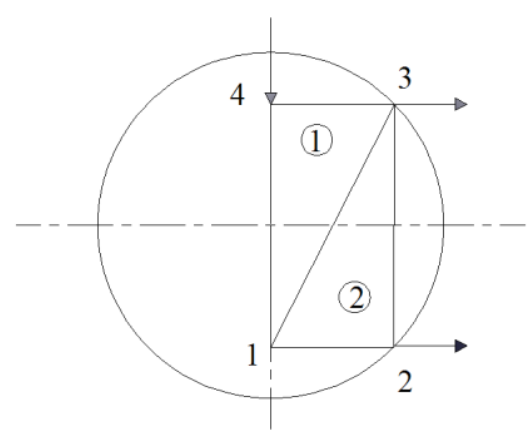

Fig 1. Represent Shaft loading

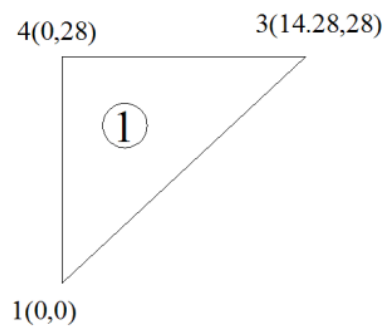

Fig.3. Element 1

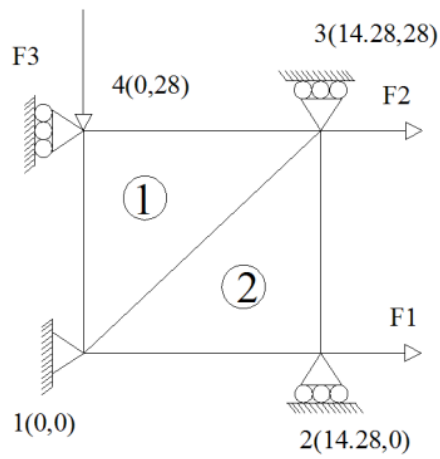

Fig.2. Elements of Shaft

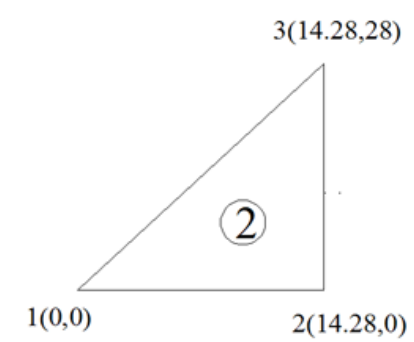

Fig.4. Element 2

From Properties of material, For SAE4140

$\mathrm{E}=2 * 105 \mathrm{~N} / \mathrm{mm} 2$ and

Coefficient of Friction for Steel to steel contact i.e. $\mu=0.7$

$$
\mathrm{D}=\frac{\mathrm{E}(1-\mu)}{(1+\mu)(1-2 \mu)}\left[\begin{array}{cccc}
1 & \frac{\mu}{1-\mu} & 0 & \frac{\mu}{1-\pi} \\
\frac{\mu}{1-\mu} & 1 & 0 & \frac{\mu}{1-\pi} \\
0 & 0 & \frac{1-2 \mu}{2(1-\mu)} & 0 \\
\frac{\mu}{1-\mu} \frac{\mu}{1-\mu} & 0 & 1
\end{array}\right]
$$

For both Element

$$
\begin{aligned}
\mathrm{J} & =\mathrm{z}_{23} \mathrm{r}_{13}-\mathrm{Z}_{13} \mathrm{r}_{23}=399.84 \\
& =399.84 \\
\mathrm{~A} & =1 / 2|\mathrm{~J}|=199.92 \mathrm{~mm}^{2}
\end{aligned}
$$

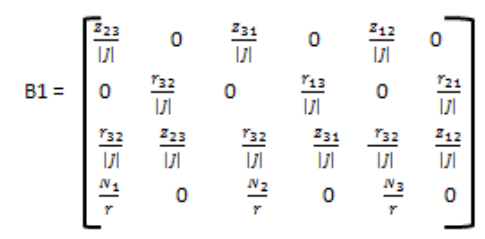

The Stiffness Matrix are obtained by Finding,

$\mathrm{K}=2 \pi \mathrm{r} * \mathrm{~A} * \mathrm{BT} * \mathrm{D} * \mathrm{~B}$ For each element

$$
\begin{array}{ll}
\text { For Element 1, } & \mathrm{K} 1=2 \pi \mathrm{r}^{*} \mathrm{~A} * \mathrm{~B} 1 \mathrm{~T} * \mathrm{D} * \mathrm{~B} 1 \\
\text { For Element 2, } & \mathrm{K} 2=2 \pi \mathrm{r}^{*} \mathrm{~A} * \mathrm{~B} 2 \mathrm{~T} \mathrm{D}^{*} \mathrm{~B} 2
\end{array}
$$

Now, Applying Boundary condition

\section{$\mathrm{F}=\mathrm{Ku}$}

Where $\mathrm{F} 1=\mathrm{F} 2=250248 \mathrm{~N}$

$\mathrm{F} 3=113796 \mathrm{~N}$

$\mathrm{U}_{2 \mathrm{x}}=43.51 \mathrm{~mm}$

$\mathrm{U}_{3 \mathrm{x}}=68.04 \mathrm{~mm}$

$\mathrm{U}_{4 \mathrm{y}}=39.15 \mathrm{~mm}$

To find the stresses in the Element Considering each element

$$
\sigma=\mathrm{D} \mathrm{B} \mathrm{U}
$$

For Element 1

$$
\sigma=\mathrm{DB}_{1} \mathrm{U}
$$

For Element 2 
$\sigma=\mathrm{D} \mathrm{B} \mathrm{B}_{2} \mathrm{U}$

Hence, it can be clearly seen that the maximum shear stresses are obtained above the given value and i.e. $402.89 \mathrm{Mpa}$

\section{Design Of Coupling}

The design of coupling is on the basis torque transmission, using ratchet and Pawl mechanism and also using the slider mechanism to restrict the relative motion between. A ratchet mechanism is based on a gear wheel and a pawl that follows as the wheel turns. When the gear is moving in one direction, the pawl slides up and over the gear teeth, sending the pawl into the notch before the next tooth. The pawl is then jammed against the depression between the gear teeth, preventing any backwards motion. Ratchet mechanisms are very useful devices for allowing linear or rotary motion in only one direction.

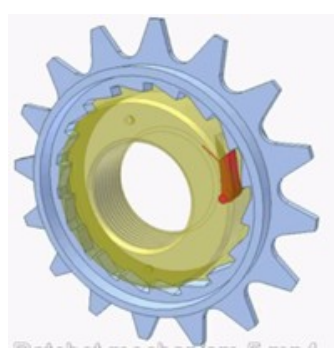

Fig. 8.1 Ratchet and Pawl used in Freewheel of Bicycle

Design of Ratchet and Pawl

Assuming the no. of teeth of ratchet (z)

$$
\mathrm{Z}=15
$$

The Pitch angle $\emptyset=\frac{360}{z}=\frac{360}{15}$

$$
\emptyset=24^{\circ}
$$

Circumference Force on the Coupling $(\mathrm{Fc})$

$$
\mathrm{Fc}=\mathrm{Tc} / \mathrm{r} 1
$$

Tc - Torque on coupling $=1281 \mathrm{~N}-\mathrm{m}$

R1 -Radius of Ratchet $=42.5 \mathrm{~mm}$

$\mathrm{Fc}=1281 / 0.0425$

$\mathrm{Fc}=30141 \mathrm{~N}$

Bending Stresses on Ratchet

Where:

$$
\mathrm{Fb}=\sigma_{\mathrm{b}} * \mathrm{~b} * \mathrm{e}^{2} /(6 * \mathrm{~b} * \mathrm{SF})
$$

$$
\begin{aligned}
\sigma_{\mathrm{b}} & =\text { Bending Stresses } \\
\mathrm{b} & =\text { Face Width }(\mathrm{mm}) \\
\mathrm{e} & =\text { Root length }(\mathrm{mm}) \\
\mathrm{e} & =\text { Depth of teeth }(\mathrm{h}) * \tan (60-(360 / \mathrm{z})) \\
\mathrm{h} & =\text { Depth of teeth }(\mathrm{mm}) \\
\mathrm{SF} & =\text { Factor of Safety } \\
\mathrm{r}_{\mathrm{f}} & =\text { Tooth root radius }(\mathrm{m}) \\
\mathrm{r}_{\mathrm{f}} & =(\text { Outside Dia. }(\mathrm{D})-(2 \mathrm{~h})) /(2000)
\end{aligned}
$$

From Catalog of SRT- SBT (Page No. 3)

a) Ratchet

No. of Teeth $=15$

Pitch $=12.56 \mathrm{~mm}$

Outside Data $=200 \mathrm{~mm}$

Face width $=25 \mathrm{~mm}$

Depth of Teeth $=7.4$

b) Pawl (Size of Pawl is based on Ratchet)

Diameter of Ratchet rod $=8 \mathrm{~mm}$

Face width of Pawl $=25 \mathrm{~mm}$

Pitch of Ratchet $=12.56 \mathrm{~mm}$

Material Properties (Catalog SRT-SBT) AISI 1046

Taking Factor of Safety FS =2

Allowable Stresses are 
$\mathrm{T}=310 \mathrm{Mpa}$

$\sigma_{\mathrm{b}}=257.5 \mathrm{Mpa}$

Calculation for Bending Stresses

a) $\mathrm{e}=$ Root length $=$ depth of teeth $(\mathrm{h}) \times \tan (60-360 / \mathrm{z})$

$\mathrm{e}=6.24 *(\tan (60-(360 / 15))$

$\mathrm{e}=4.54$ (depth of teeth $=6.24)$

b) $\mathrm{rf}=$ teeth root radius $=$

$=($ Outside Dia. $(\mathrm{D})-2 \mathrm{~h}) / 2000$

$=(180-(2 * 6.24) / 2000)$

$=0.08376$

$\mathrm{Fb}=1772 \mathrm{~N}$

Torque required rotating the Roll of Pay-off System

$\mathrm{T}=\mathrm{Fb} \times \mathrm{rf}$

$\mathrm{T}=148.42 \mathrm{~N}-\mathrm{m}<$ Torque of Gear motor i.e. $=1281 \mathrm{~N}-\mathrm{m}$

Bending stress calculation for Ratchet and Pawl

As Ratchet and Pawl is of same Material so,

For Ratchet

Bending Force $(\mathrm{Fb})=\sigma \mathrm{b} \times \mathrm{A}$

A - Area of Bending $=$ Area of Contact of Pawl and ratchet

$A=$ Face width $(b) \times$ surface of contact $(h)$

$\mathrm{A}=75 \mathrm{~mm} 2$

Bending Stresses $(\sigma \mathrm{b})=\mathrm{Fb} / \mathrm{A}=23.62 \mathrm{MPa}<$ Allowable Shear Stress $=257 \mathrm{MPa}$

Bending Stress on Powel

Bending Force $(\mathrm{Fb})=\sigma \mathrm{b} \times \mathrm{A}$

$\mathrm{A}-$ Area of Bending $=$ Area of Contact of Pawl and ratchet

$\mathrm{A}=$ Face width $(\mathrm{b}) \times$ surface of contact $(\mathrm{h})$

Surface contact of Pawl with Ratchet $(\mathrm{h})=2 \mathrm{~mm}$ (Circular surface has line contact)

$\mathrm{A}=50 \mathrm{~mm}^{2}$

Bending Stresses $(\sigma \mathrm{b})=\mathrm{Fb} / \mathrm{A}=35.42 \mathrm{MPa}<$ Allowable Shear Stress $=257 \mathrm{MPa}$

Shear Stresses on the Inserts of Coupling

Shear Force on the shaft of coupling $(\mathrm{Ft})=\tau \times \mathrm{A}$

r- radius of Insert $=15 \mathrm{~mm}$

$$
\mathrm{F}_{\mathrm{t}}=\frac{\mathrm{T}}{\mathrm{r}}=\frac{1281}{0.068}=21350 \mathrm{~N}
$$

Shear Stresses $\tau=\mathrm{Ft} / \mathrm{A}=21350 /((\pi / 4) * 152)$

$\tau=120 \mathrm{Mpa}<$ allowable Stresses of Material= $310 \mathrm{Mpa}$

All the Stresses in Insert of Coupling, Ratchet and Pawl are less than allowable Stresses Hence, Design of Coupling is Safe.

\section{Result \& Conclusion}

The analytical and FE analysis of shaft of gear motor are compared for all cases. The analytical analysis for the static analysis indicates the stresses increases during the impact loads. The tabular representation of the analytical \& Inventor compared with the allowable stresses. From the table for both the cases the maximum shear stress value obtained by Impact loading is greater than the allowable stress which results in sudden failure of shaft.

Table IV

\begin{tabular}{|c|c|c|c|c|}
\hline Stresses & Analytical Results & Inventor Results & FEM Results & Allowable limit \\
\hline Max Shear Stresses (MPa) & $388 \mathrm{Mpa}$ & $472 \mathrm{Mpa}$ & $402.89 \mathrm{Mpa}$ & $187.5 \mathrm{Mpa}$ \\
\hline
\end{tabular}

The FE analysis is also shows the region of high stresses at the step of $60 \mathrm{~mm}$ diameter near bearing region from which the failure is known to happen frequently. Hence analysis proves that the shaft is heavily loaded and on some instances like while processing higher gauge material responsible for the extra tractive effort developed on the shaft Further the actual loading condition would have the additional load or shocks due 
to improper tension, jerk, and vibration and overloading, misalignment of shaft of gear motor, traction variation at exit section etc. This entire factor shall contribute to increase in the load and hence the stress also increased.

So, my suggestion related to newly Designed coupling mentioned in the thesis will definitely help to reduce on the stresses on the shaft of motor.

Design of coupling in on the basis of Freewheel of Bicycle whose working is to provide one direction rotation and restrict other, means it rotate freely when disengage and when engage it rotate with shaft of Roll and only Motor torque in action not the Main CRM system Torque. Hence use of newly designed coupling reduces the failure rate of shaft of Gear motor.

Bending Stresses on the teeth of Ratchet and Pawl are analytically found out and all are less than the allowable stresses i. e. Calculated bending Stresses (34.42 Mpa) and allowable stresses are $257 \mathrm{Mpa}$ in both of the component i.e. ratchet and Pawl.

Ratchet gearing may be used to transmit intermittent motion, or its only function may prevent the ratchet wheel from rotating backward. Ratchet gearing of this latter form is commonly used in connection with hoisting mechanisms of various kinds, to prevent the hoisting drum or shaft from rotating in a reverse direction under the action of the load.

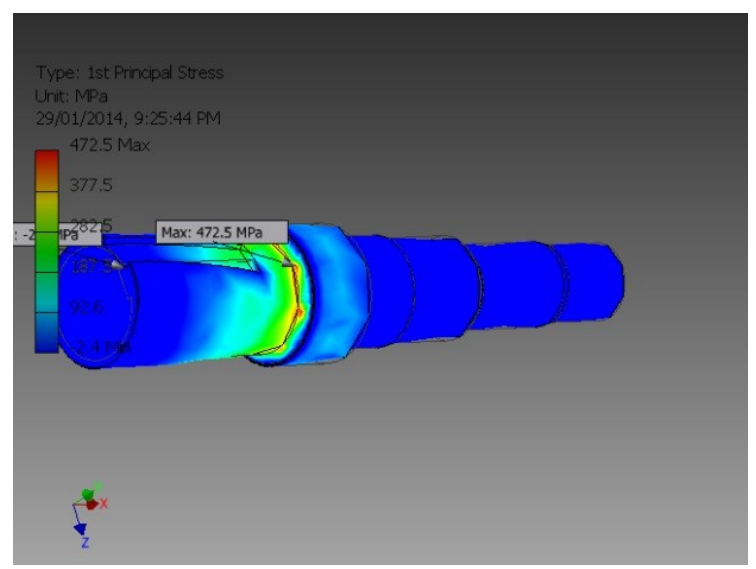

Fig.5. Shear Stresses on shaft of gear motor

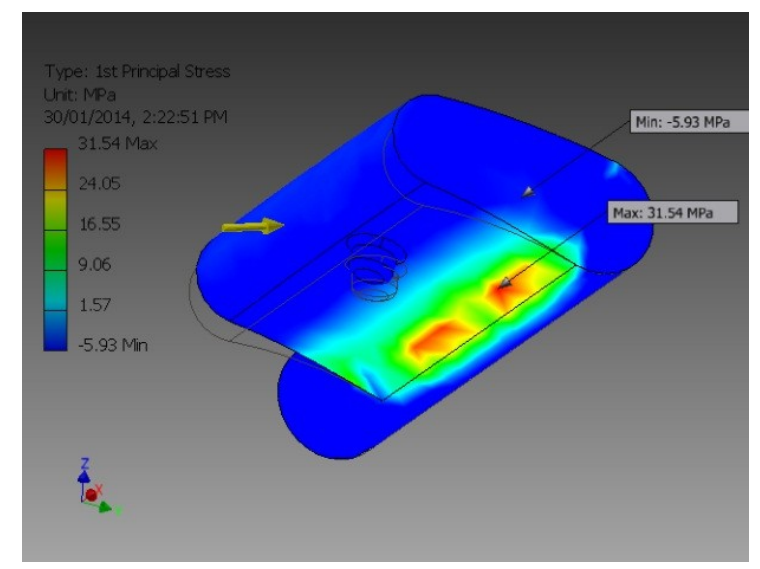

Fig .6. Maximum bending stresses on Pawl

\section{Conclusion}

The studies executed in the scope of stress analyses of the shaft of gear motor have revealed the followings:

1. Stress analyses performed by both analytical and Inventor-12.0 software show that maximum stresses are generated at step of $40 \mathrm{~mm}$ diameter near bearing zone. This indicates that impact loading near that zone i.e. shaft at least end of step $40 \mathrm{~mm}$ diameter fails suddenly due to over loading.

2. The component to be preventing failure, Max Shear Stresses should be less than yield strength of material. In this case it is greater than the allowable yield strength of material considering FOS 1 which is generally considered for the mechanical structural components.

3. The static loading for bending stress up to $512 \mathrm{~N} / \mathrm{mm} 2$ but maximum shear stress is $472 \mathrm{~N} / \mathrm{mm} 2$, which is exceeding the allowable stress of $187.5 \mathrm{~N} / \mathrm{mm} 2$. This result in sudden failure of drive end shaft.

4. May one of the reason for sudden failure is lack of concentration of worker during operation.

5. As Ratchet gearing may be used to transmit intermittent motion, or its only function may be to prevent the ratchet wheel from rotating backward. Ratchet gearing of this latter form is commonly used in connection with hoisting mechanisms of various kinds, to prevent the hoisting drum or shaft from rotating in a reverse direction under the action of the load.

6. Bending stresses in teeth of ratchet wheel and in pawl are calculated and all the stresses are less than the allowable stresses, ie .calculated stresses are 17.71Mpa and allowable stresses are 257Mpa, hence design of coupling is safe.

\section{Future scope}

1. Selecting proper material for shaft having stresses more than $2504 \mathrm{Mpa}$, so shaft may sustain in the maximum loading and impact loading condition.

2. Developed design of shaft according to the stresses induced in the shaft and modify diameter, machined it, use in the motor that in the scrap. So company gets its total value.

3. Select the Proper model of motor having the least diameter of shaft is more than $75 \mathrm{~mm}$.

4. Maintain the speed of both Gear motor and motor of cold rolling mill by installing new gear box for cold rolling mill .disengagement of Gear motor Shaft from pinch roll of Pay-OFF goes easy. 
5. May include rotation policy for worker those working on cold rolling mill after four hour work.

6. Dynamic analysis of shaft of gear motor should be carried out.

7. Dynamic analysis of Coupling has to be carried which may helpful in vast of application in engineering field.

\section{Referances}

[1] Osman Asi " Fatigue failure of a rear axle shaft of an automobile"- Engineering Failure Analysis 13 (2006) 1293-1302

[2] M. Ristivojevic, R. Mitrovic, T. Lazovic "Investigation of Causes of Fan Shaft Failure"-Engineering Failure Analysis 17 (2010) $1188-1194$

[3] Sandip Bhattacharyya "Failure Analysis of Gas Blower Shaft of a Blast Furnace"- Engineering Failure Analysis 15 (2008) $349-355$

[4] R.W. Fuller "Failure analysis of AISI 304 stainless steel shaft" - Engineering Failure Analysis 15 (2008) 835-846

[5] M. J. REID “Analysis Of The Causes Of Recent Roll Shaft Failures In Natal Sugar Mills”- Proceedings of the South African Sugar Technologists' Association - June 1988

[6] Saleh A. Al-Fozan, Anees U. Malik and Mohammad Al-Hajri "Failure Analysis Of Sheared Shaft Of A Brine Recycle Pump"Troubleshooting Technical Report No. TSR 3804/05005 in August 2005

[7] E. Rusiński, J. Czmochowski, P. Moczko "Failure Reasons Investigations Of Dumping Conveyor Breakdown"- Volume 23 Issue 1 July 2007Journal of Achievements in Materials and Manufacturing Engineering Deepan Marudachalam M.G, K.Kanthavel, R.Krishnaraj “Optimization Of Shaft Design Under Fatigue Loading Using Goodman Method”- International Journal of Scientific \& Engineering Research Volume 2, Issue 8, August-2011 2 ISSN 2229-5518

[8] Jim Colvin "ESD Failure analysis Methodology"-Microelectronics Reliability 38(1998) 1705-1714

[9] DRG No. 03/CGL IV / 014, "Shaft of gear motorǿ $1050 * 1500$ mm", Ispat Industries ltd, Kalmeshwar.

[10] Johan Martinsson "Fatigue Assessment of Complex Welded Steel Structures" TRITA-AVE 2005:02, ISBN 91-2783-968-6

[11] A.H. Bonnett, "Root Cause AC Motor Failure Analysis with a Focus on Shaft Failures",IEEE Trans. Industry Application, 36(5), 11971209,2000

[12] DejanMomcilovic "Failure analysis of hydraulic turbine shaft"'Engineering Failure Analysis 20 (2012) 54-66

[13] H.L. Pan *,"Failure analysis of a rotating cantilever shaft in chloride corrosive environment" Engineering Failure Analysis 13 (2006) 646-655

[14] N. Parida "Failure analysis of coal pulverizer mill shaft" Engineering Failure Analysis 10 (2003) 733-744

[15] S.K. Bhaumik "Fatigue failure of a hollow power transmission shaft" Engineering Failure Analysis 9 (2002) $457-467$

[16] Failure and Root Cause Analysis by TCR Engineering “Investigating Material and Component Failure” Jul 2004

[17] SRT-SBT Catalogs

[18] B. D. Shivalkar "Design Data book “ 